\title{
ISO-1, a Macrophage Migration Inhibitory Factor Antagonist, Inhibits Airway Remodeling in a Murine Model of Chronic Asthma
}

\author{
Pei-Fen Chen, ${ }^{1,2^{*}}$ Ya-ling Luo, ${ }^{1}$ Wei Wang,${ }^{3 *}$ Jiang-xin Wang, ${ }^{4}$ Wen-yan Lai, ${ }^{5}$ Si-ming Hu, ${ }^{1}$ Kai Fan Cheng, ${ }^{6}$ \\ and Yousef Al-Abed ${ }^{6}$
}

Departments of ${ }^{1}$ Respiratory Diseases and ${ }^{5}$ Cardiology, Nanfang Hospital, Southern Medical University, Guangzhou, China; ${ }^{2}$ ShenZhen Third People Hospital, Guangdong, China; ${ }^{3}$ Nanfang Hospital, Southern Medical University, Guangzhou, China; ${ }^{4}$ School of Life Sciences, Arizona State University, Tempe, Arizona, United States of America; ${ }^{6}$ Laboratory of Medicinal Chemistry, Feinstein Institute for Medical Research, Manhasset, New York, United States of America

\begin{abstract}
Airway remodeling is the process of airway structural change that occurs in patients with asthma in response to persistent inflammation and leads to increasing disease severity. Drugs that decrease this persistent inflammation play a crucial role in managing asthma episodes. Mice sensitized (by intraperitoneal administration) and then challenged (by inhalation) with ovalbumin (OVA) develop an extensive eosinophilic inflammatory response, goblet cell hyperplasia, collagen deposition, airway smooth muscle thickening, and airway wall area increase, similar to pathologies observed in human asthma. We used OVA-sensitized/challenged mice as a murine model of chronic allergic airway inflammation with subepithelial fibrosis (i.e., asthma). In this OVA mouse model, mRNA and protein of macrophage migration inhibitory factor (MIF) are upregulated, a response similar to what has been observed in the pathogenesis of acute inflammation in human asthma. We hypothesized that MIF induces transforming growth factor- $\beta 1$ (TGF- $\beta 1$ ) synthesis, which has been shown to play an important role in asthma and airway remodeling. To explore the role of MIF in the development of airway remodeling, we evaluated the effects of an MIF small-molecule antagonist, (S,R)3-(4-hydroxyphenyl)-4,5-dihydro-5-isoxazole acetic acid methyl ester (ISO-1), on pathologies associated with the airway-remodeling process in the OVA mouse model. We found that administration of ISO-1 significantly mitigated all symptoms caused by OVA treatment. In addition, the treatment of OVA-sensitized mice with the MIF antagonist ISO-1 significantly reduced TGF- $\beta 1$ mRNA levels in pulmonary tissue and its protein level in bronchial alveolar lavage fluid supernatants. We believe the repression of MIF in the ISO1 treatment group led to the significant suppression observed in the inflammatory responses associated with the allergen-induced lung inflammation and fibrosis in our murine asthma (OVA) model. Our results implicate a possible function of MIF in the pathogenesis of chronic asthma and suggest that MIF might be an important therapeutic target for airway remodeling.
\end{abstract}

(c) 2010 The Feinstein Institute for Medical Research, www.feinsteininstitute.org

Online address: http://www.molmed.org

doi: 10.2119/molmed.2009.00128

\section{INTRODUCTION}

Asthmatic airway remodeling, characterized by structural and morphometric changes of the airway epithelium, is believed to be the result of chronic inflammation in the bronchial wall. The marked features of airway remodeling include subepithelial fibrosis (excess deposition of collagen in the subepithe- lial layer) (1) and goblet cell (GC) hyperplasia and metaplasia (2). Airway remodeling has been speculated to be one of the factors that makes asthma difficult to cure (3).

Current guidelines for asthma treatment emphasize the use of bronchodilators to rescue or delay exacerbation of symptoms, and inhaled corticosteroids to

${ }^{*} P$-FC and WW contributed equally to this paper.

Address correspondence and reprint requests to Ya-ling Luo, Department of Respiratory Diseases, Nanfang Hospital, Southern Medical University, Guangzhou, 510515, China.

Phone: 13725480661; E-mail: luoyaling08@sohu.com.

Submitted September 16, 2009; Accepted for publication April 13, 2010; Epub

(www.molmed.org) ahead of print May 14, 2010.

minimize the underlying inflammation. Despite the role of inhaled corticosteroids in prevention of inflammation (4) and reduction of airway remodeling (5), these drugs have potential adverse side effects, such as oral candidiasis and dysphonia (6). Furthermore, it is estimated that a subset of asthmatic patients $(10 \%$ to $25 \%$ ) do not respond to glucocorticoid therapy (7-10). Hence, there is urgent need for additional therapies in asthma because such a large number of asthmatic patients remain symptomatic with glucocorticoid therapy.

Previous efforts have been devoted to exploring the potential function of macrophage migration inhibitory factor 
(MIF) in asthma, because MIF has been shown to function as a steroid antagonist (11). In a murine MIF knockout study it was demonstrated that MIF was required for allergic asthma (12). Using $\mathrm{MIF}^{-/-}$ mice, Mizue and colleagues also demonstrated that OVA aerosol-challenged mice showed less pulmonary inflammation and lower-airway hyperresponsiveness than wild-type controls (13). Blockade of MIF by anti-MIF antibody prevented the antigen-induced response in a murine model of allergic airway inflammation (14). However, there are currently no reported data regarding whether blockade of MIF can exert an influence on airway remodeling. MIF can induce mRNA and protein levels of the transforming growth factor $\beta 1$ (TGF- $\beta 1$ ) in a time- and dose-dependent pattern in cultured mesangial cells (15). It is believed that TGF- $\beta 1$ has a prominent role in airway remodeling. TGF- $\beta 1$ could increase [3H]thymidine incorporation and number of airway smooth muscle cells (ASMC) in a concentration-dependent manner in serum-free medium, and TGF- $\beta 1$ also enhanced serum-induced ASMC proliferation (16). Furthermore, TGF- $\beta 1$ could enhance collagen gene expression, extracellular matrix accumulation, fibroblast proliferation and myofibroblast differentiation $(17,18)$.

To investigate the effects of MIF on the development of airway remodeling, we administered an MIF small molecule antagonist, (S,R)3-(4-hydroxyphenyl)-4,5dihydro-5-isoxazole acetic acid methyl ester (ISO-1), to mice sensitized (by intraperitoneal administration) and then challenged (by inhalation) with ovalbumin (OVA). We set out to explore whether chronic treatment of these chronic asthma (OVA) model mice with ISO-1 could prevent the collagen deposition, bronchial wall area increase and GC hyperplasia associated with airway remodeling in OVA model mice. We also studied the effect of ISO-1 administration on TGF- $\beta 1$ mRNA in lung tissue and TGF- $\beta 1$ levels in bronchial alveolar lavage fluid (BALF) to determine if TGF- $\beta 1$ was a possible downstream tar- get of MIF inhibition and played a role in the process of airway remodeling.

\section{Materials and Methods}

\section{Agents}

ISO-1 was synthesized as described previously (19). OVA (grade V) and dexamethasone (DEX) were purchased from Sigma-Aldrich (St. Louis, MO, USA).

Aluminum hydroxide was obtained from Pierce Biotechnology (Rockford, IL, USA). The monoclonal antibody against MIF was from Santa Cruz Biotechnology (Santa Cruz, CA, USA). SP kit was purchased from Zhongshan Goldenbridge Biotechnology (Zhongshan, GD, China), Moloney-murine leukemia virus (M-MLV) reverse transcriptase from Promega (Madison, WI, USA), oligo dT from Invitrogen (Carlsbad, CA, USA), RNAeasy kit from Qiagen Technical Services (Melbourne, Australia) and TGF- $\beta 1$ enzyme-linked immunosorbent assay kit from R\&D Systems (Minneapolis, MN, USA).

\section{Animals}

Six-week-old female C57BL / 6 mice were purchased from the Southern Medical University Animal Center and maintained in the same center. All experimental procedures were approved by the animal care and use committee of the Southern Medical University.

\section{Murine Model of Chronic Asthma}

The model was made according to Jain et al. (20). Briefly, mice were sensitized by means of intraperitoneal injection of OVA $(10 \mu \mathrm{g})$ precipitated with aluminum hydroxide $(100 \mu \mathrm{g})$ on $\mathrm{d} 0$ and 14 . After that, these mice were given $35 \mathrm{mg} / \mathrm{kg}$ of ISO-1 (ISO-1 group), $10 \mathrm{mg} / \mathrm{kg}$ DEX (DEX group) or $0.2 \mathrm{~mL}$ phosphatebuffered saline (PBS) (OVA [vehicle control] group) by means of intraperitoneal injection $0.5 \mathrm{~h}$ before each OVA challenge (nebulized $2.5 \%$ solution $30 \mathrm{~min} / \mathrm{d}$, $3 \mathrm{~d} / \mathrm{wk}$ for $6 \mathrm{wks}$ ). Mice were killed $24 \mathrm{~h}$ after the last OVA inhalation. Control groups were injected intraperitoneally with PBS and inhaled aerosolized PBS at the same time as the other three groups. Mice treated with ISO-1 or DEX but without OVA sensitization were also set up as controls.

\section{BALF and Cellular Analysis}

Twenty-four $\mathrm{h}$ after the last challenge, the mice were anesthetized and placed in the supine position with the head tilted back, and then the trachea was cannulated. Right lungs were cut for mRNA isolation, and left lungs were lavaged three times with $0.3 \mathrm{~mL}$ of sterile PBS. The BALF was immediately centrifuged (5 $\mathrm{min}, 4^{\circ} \mathrm{C}, 151 \mathrm{~g} / \mathrm{min}$ ). Cell pellets were resuspended in $1 \mathrm{~mL}$ PBS for total and differential cell counting, and the supernatants were rapidly collected and frozen for further investigation. Differential cell counting was performed on hematoxylin and eosin (H\&E)-stained cytospins. On each cytospin 200 to 500 cells were counted.

\section{Measurement of TGF- $\beta 1$ in BALF}

The concentrations of TGF- $\beta 1$ in BALF supernatants were assayed by enzymelinked immunosorbent assay. In this assay the minimal detection limit for TGF- $\beta 1$ was $<7 \mathrm{pg} / \mathrm{mL}$.

\section{RNA Isolation and Reverse Transcription-Polymerase Chain Reaction Analysis of MIF and TGF- $\beta 1$ mRNA}

Total RNA was isolated from lungs by the RNAeasy kit (Qiagen). One microgram of total RNA was reverse transcribed by using M-MLV reverse transcriptase (Promega) and oligo dT (Invitrogen) according to the manufacturers' instructions. Polymerase chain reaction (PCR) was performed by denaturation ( $5 \mathrm{~min}$, $94^{\circ} \mathrm{C}$ ) followed by 36 cycles of denaturation $\left(45 \mathrm{~s}, 94^{\circ} \mathrm{C}\right)$, annealing $\left(45 \mathrm{~s}, 53^{\circ} \mathrm{C}\right)$ and extension $\left(1 \mathrm{~min}, 72^{\circ} \mathrm{C}\right)$, then ended with final extension $\left(10 \mathrm{~min}, 72^{\circ} \mathrm{C}\right)$. PCR products were separated in $1.5 \%$ agarose gels, stained with ethidium bromide and visualized under ultraviolet light. Densitometric scanning of the agarose gels was performed, and the relative amount of each gene mRNA expression was deter- 
mined by normalization to the $\beta$-actin mRNA detected in the same sample.

Primers for detecting MIF were 5'-CGGCAAGCCCGCACAGTACATC-3' (forward) and 5'-CACGTTGGCAGCGTT CAT-3' (reverse) with an expected size of $229 \mathrm{bp}$. The forward primer for TGF- $\beta 1$ was 5'-CCCACTGATACGCCTGAG-3' and the reverse primer was 5'-AGACA GAAGTTGGCATGGTAG-3'. The size of the amplicon was 404 bp. $\beta$-actin mRNA was analyzed by using primers as 5'-AGGGAAATCGTGCGTGACAT-3' (forward) and 5'-CATCTGCTGGAAGGT GGACA-3' (reverse), and the size of the amplicon was $450 \mathrm{bp}$.

\section{Histopathology}

After lavage, lungs were removed and fixed in paraformaldehyde, and tissue blocks were embedded in paraffin. Lung sections underwent deparaffinization and hydration for staining. H\&E staining was used to evaluate airway smoothmuscle thickness and airway wall area. For enumeration of mucin-positive GCs, Alcian blue and periodic acid-Schiff stains were used (21). Sections were stained with Masson Trichrome stain to evaluate collagen deposition.

\section{Morphometry}

Images of airway sections were randomly obtained at $20 \times$ magnification with an RT Color Digital camera (Diagnostic Instruments, Sterling Heights, MI, USA). Airways with a ratio of maximum to minimum internal diameter no less than 2 were considered as cut obliquely and were not included $(22,23)$. Briefly, five images were analyzed per section by using Image Pro-Plus software 6.0 (IPP 6.0) calibrated with a reference micrometer slide. For airway wall area measurement, the basement membrane perimeter $\left(\mathrm{P}_{\mathrm{bm}}\right)$ and total wall area $\left(\mathrm{WA}_{\mathrm{t}}\right)$ were measured at $200 \times$ magnification. Airway wall area was normalized to $\mathrm{Pi}\left(\mathrm{WA}_{\mathrm{t}} / \mathrm{P}_{\mathrm{bm}}\right)$ (23). Airway smooth-muscle thickness was also evaluated in H\&E-stained lung sections by measuring the thickness of the smooth-muscle cell layer beneath the airway epithelial cell basement mem- brane (21). GC hyperplasia was assessed in PAS-stained lung sections and expressed as cells / $100 \mu \mathrm{m}$ basement membrane according to the method of Hendson and colleagues (21). Collagen deposition was expressed as the area of trichrome staining per micron length of basement length of the basement membrane of bronchioles.

\section{Immunohistochemical Study}

Immunohistochemical analysis was performed according to the manufacturer's protocol on paraffin-embedded tissue (Zhongshan). The primary antibody against MIF was diluted 1:200 with PBS. Routine immunohistochemical analysis was used in this study. Briefly, the goat horseradish-peroxidase-conjugated antirabbit IgG (Zhongshan) and freshly made 3,3'-diaminobenzidine were used. The tissue sections were counterstained with hematoxylin and mounted. Bronchial epithelium staining intensity was assessed quantitatively on coded material by light microscopy by using IPP 6.0 and expressed as integrated absorbency.

\section{Data Analysis}

Data are represented as the mean \pm SEM. Statistical significance was analyzed by means of ANOVA (SPSS 13.0). A $P$ value of less than 0.05 was considered significant. When statistic significance was reached, post hoc test (the LSD test or Games-Howell) was performed.

\section{RESULTS}

\section{MIF Expression in Chronic Asthmatic Mice}

To determine whether MIF is expressed in this model, we first evaluated the expression of MIF at mRNA and protein levels in mouse pulmonary tissue. Compared with the control group, the OVA-challenged group had a higher MIF mRNA level, and DEX administration inhibited this increase. (Figure 1, Table 1, $P<0.01$, respectively). Histological examination using the pulmonary tissue confirmed that positive immunostaining

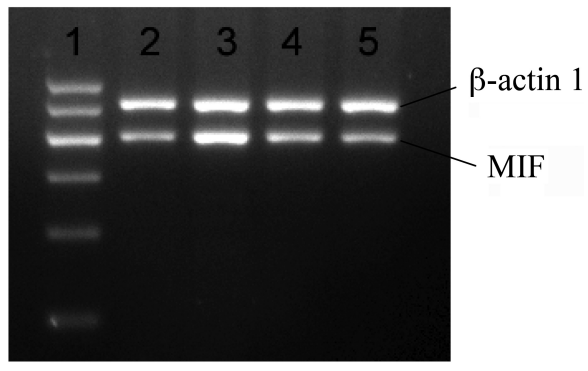

Figure 1. Pulmonary expression of MIF mRNA. Reverse transcription-polymerase chain reaction was performed to examine mRNA expression of MIF in mice lung tissue. Expression of housekeeping gene $\beta$-actin 1 mRNA was detected as a control. Lane 1: marker; lane 2: control; lane 3: OVA; lane 4: ISO-1; lane 5: DEX.

of MIF protein was observed in bronchial epithelial cells in the control group. In the OVA group, positive immunostaining for MIF was observed in epithelial submucosa and inflammatory cells in the alveoli; the administration of DEX prevented the increases (Figure 2, $P<0.01$, respectively). The mRNA and protein expression of MIF in control mice treated with ISO-1 or DEX without OVA sensitization showed no significant difference compared with those of controls (data not shown).

\section{ISO-1 Reduces Airway Inflammation}

In contrast to vehicle control mice, significantly increased numbers of eosinophils, lymphocytes and total cells in BALF were detected in OVA-challenged mice, which were inhibited by administration of DEX and ISO-1. By light microscopy, an extensive eosinophilic and mononuclear cell infiltration around the

Table 1. Relative expression of MIF and TGF- $\beta 1$ mRNA in C57/BL6 mice $(n=8)$.

\begin{tabular}{lcc} 
Group & MIF mRNA & TGF- $\beta 1 \mathrm{mRNA}$ \\
\hline Control & $1.41 \pm 0.38^{a}$ & $0.39 \pm 0.06^{a}$ \\
OVA & $2.14 \pm 0.29^{b}$ & $0.67 \pm 0.08^{b}$ \\
ISO- 1 & $1.91 \pm 0.24^{b}$ & $0.50 \pm 0.08^{a, b}$ \\
DEX & $1.61 \pm 0.30^{a}$ & $0.43 \pm 0.07^{a}$ \\
\hline
\end{tabular}

a $P<0.01$ versus OVA group.

${ }^{\mathrm{b}} P<0.01$ versus control group. 

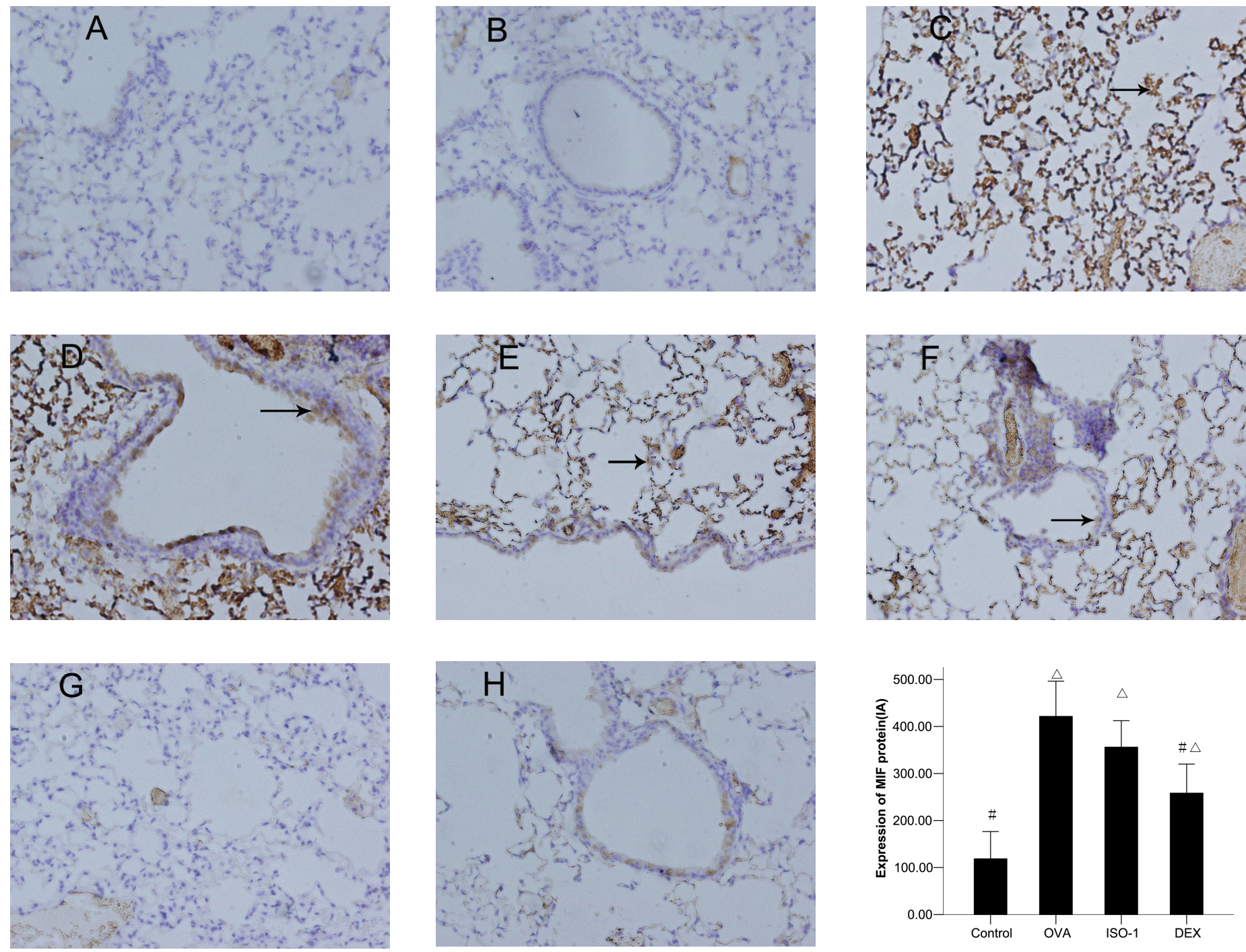

Figure 2. Immunohistochemistry of macrophage MIF in the lung was assessed quantitatively by using IPP 6.0 and expressed as integrated absorbency $(I A)$. (A, B) MIF was weakly detected in airway in the control group (Control; $n=8$ ). (C,D) MIF was prominent in airway in the ovalbumin group(OVA; $n=8$ ) after the OVA challenge. (E,F) MIF was prominent in the airway in the ISO-1 group (ISO-1; $n=8)$. (G, $\mathrm{H}$ ) MIF was weakly detected in the airway in the DEX group (DEX; $n=8$ ) (original magnification: $\times 200){ }^{\#} P<0.01$ versus OVA group; $\triangle P<0.01$ versus control group.

pulmonary blood vessels and airways was observed in the lung interstitium of OVA-sensitized mice compared with control groups. DEX and ISO-1 inhibited the cell infiltration of the lung tissue in the OVA group (Figure 3, $P<0.01$ or $P<$ 0.05). In mice treated with ISO-1 or DEX but without OVA sensitization, eosinophils, lymphocytes and total cells in BALF were observed to be no different compared with those of control (data not shown).

\section{ISO- 1 Reduces Airway Wall Area}

OVA-challenged mice revealed significantly increased airway wall area compared with controls (Figure $4, P<0.01$ ), and treatment of mice with DEX or ISO-1 significantly reduced the increases (control, $5.59 \pm 1.44 \mu \mathrm{m}^{2} / \mu \mathrm{m}$; OVA, $11.98 \pm$ $3.13 \mu \mathrm{m}^{2} / \mu \mathrm{m}$; ISO-1, $7.99 \pm 1.70 \mu \mathrm{m}^{2} / \mu \mathrm{m}$; DEX, $7.93 \pm 1.44 \mu \mathrm{m}^{2} / \mu \mathrm{m}$; Figure 4 , all $P<0.05)$. There was no significant difference between ISO-1 group and DEX group $(P>0.05)$. Airway wall area in mice treated with ISO-1 or DEX without OVA sensitization showed no significant difference compared with controls (data not shown).

\section{ISO-1 Reduces Airway Smooth- Muscle Hypertrophy}

OVA-sensitized/challenged animals had a significantly increased airway smooth muscle thickness compared with control animals $(7.52 \pm 2.82 \mu \mathrm{m}, 2.27 \pm 1.09$ $\mu \mathrm{m}, P<0.01$, respectively). ISO-1 and DEX 

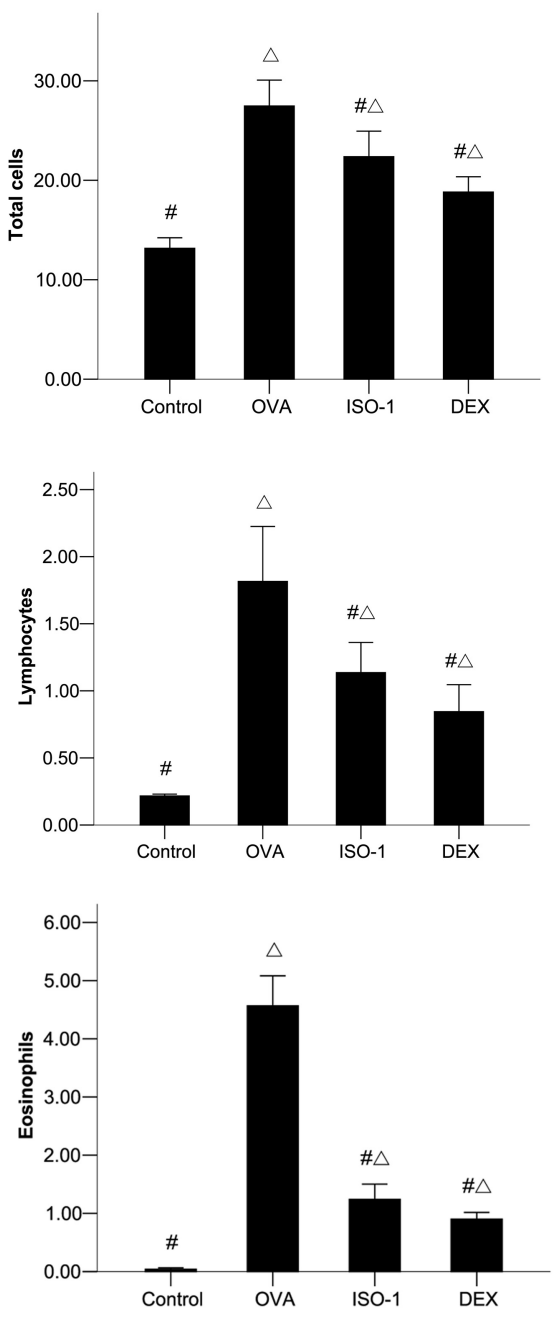

Figure 3. Total and differential cell counts in BALF. The numbers of total cells, lymphocytes and eosinophils were significantly elevated in the OVA group compared with the control group $\left(\times 10^{5}\right)$. Treatment with ISO-1 and DEX significantly decreased the numbers of total cells, lymphocytes and eosinophils. ${ }^{\triangle} P<0.01$ versus control group; ${ }^{\#} P<0.01$ versus OVA group.

treatment reduced the airway smooth muscle hypertrophy significantly (ISO-1, $4.19 \pm 1.45 \mu \mathrm{m}$; DEX, $4.09 \pm 1.10 \mu \mathrm{m}$ ) (Figure $5, P<0.01$, respectively, OVA versus ISO-1 or DEX). There was not a significant difference between the ISO-1 group and DEX group $(P>0.05)$. Airway smooth muscle thickness in mice treated with ISO-1 or DEX but without OVA sensitization was observed to be no different compared with those of controls (data not shown).
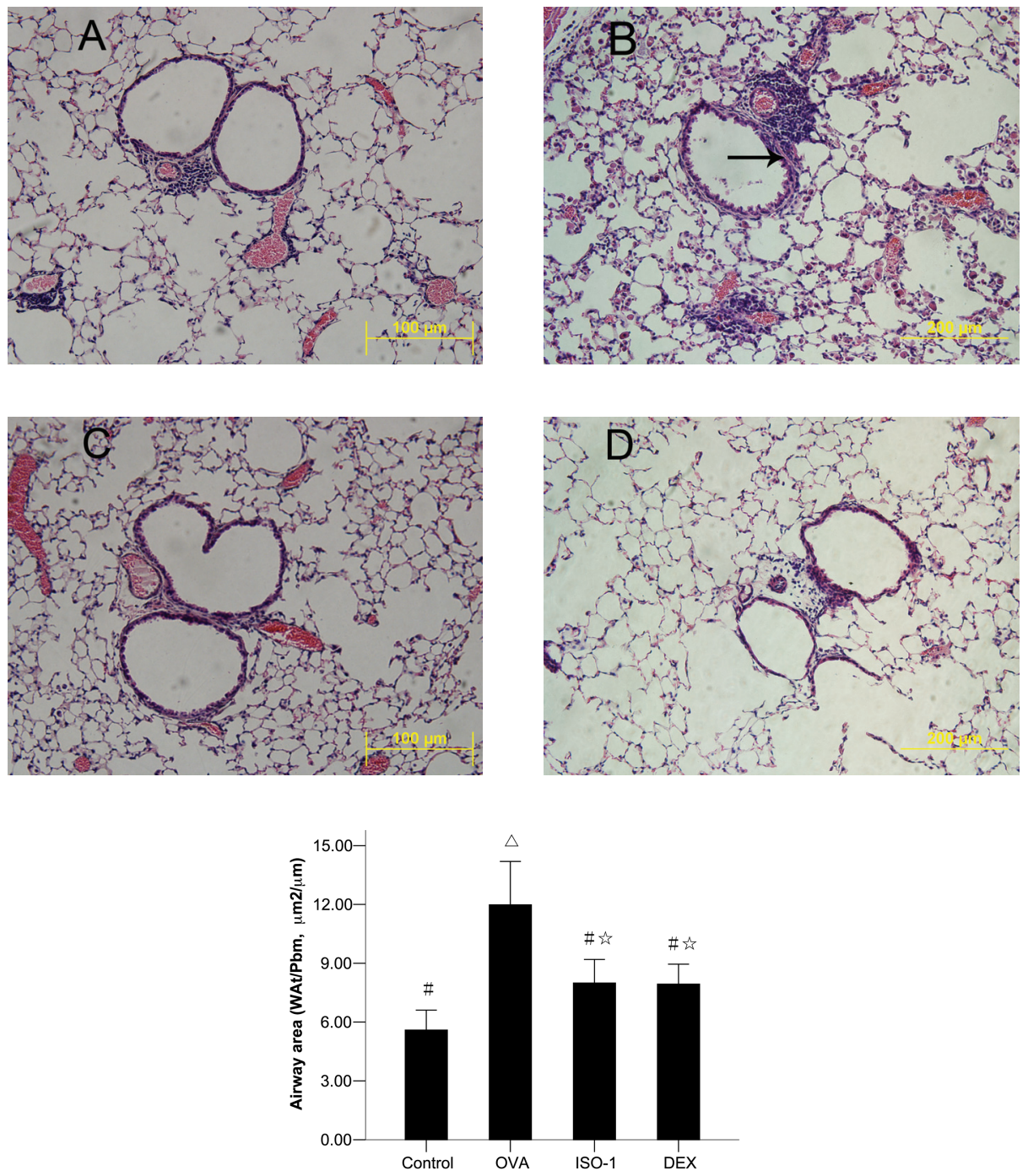

Figure 4. ISO-1 and DEX reduced OVA-induced increased airway wall area. Lung tissue was stained with H\&E. (A) Control; (B) OVA; (C) ISO-1; (D) DEX. ${ }^{\triangle} P<0.01$ versus control group; $P<0.05$ versus control group; ${ }^{\#} P<0.01$ versus OVA group. (Magnification: $200 x$, $\mu \mathrm{m}^{2} / \mu \mathrm{m}(\mathrm{B}, \mathrm{D}) ; 100 \times, \mu \mathrm{m}^{2} / \mu \mathrm{m}(\mathrm{A}, \mathrm{C})$ ).

\section{ISO-1 Inhibits Subepithelial Fibrosis}

The role of ISO-1 on deposition of collagen in the subepithelial layer has not been studied previously. We then evaluated subepithelial collagen with Masson

Trichrome stain $(21,24)$ and found a significant increase of subepithelial collagen in mice subjected to repeated exposures to OVA, which was inhibited in ISO-1 or DEX-treated mice (Figure 6, control, $3.97 \pm$ $2.69 \mu \mathrm{m}^{2} / \mu \mathrm{m}$; OVA, $20.24 \pm 9.16 \mu \mathrm{m}^{2} / \mu \mathrm{m}$; ISO-1, $7.33 \pm 2.30 \mu \mathrm{m}^{2} / \mu \mathrm{m}$; DEX, $5.13 \pm$ $2.46 \mu \mathrm{m}^{2} / \mu \mathrm{m} ; P<0.01$ or $\left.P<0.05\right)$. There was no significant difference between the ISO-1 and DEX groups $(P>0.05)$. Subepithelial collagen in mice treated with ISO-1 or DEX but without OVA sensitization were observed to have no difference compared with controls (data not shown).

\section{ISO-1 Reduces GC Hyperplasia- Metaplasia}

To evaluate GC hyperplasia-metaplasia, we stained the lung sections with Alcian blue and periodic acid-Schiff. We found a notable induction of GCs in untreated 


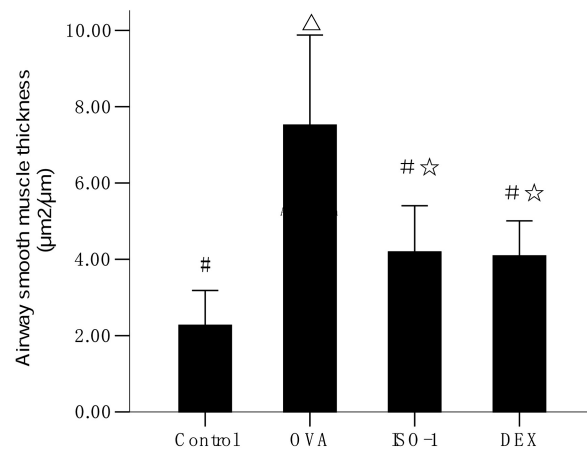

Figure 5. ISO-1 and DEX reduced OVA-induced increased airway smooth muscle thickness. Lung tissue was stained with $\mathrm{H} \& \mathrm{E}$ (original magnification: $200 x, \mu \mathrm{m}^{2} / \mu \mathrm{m}$ ). ${ }^{\triangle} P<0.01$ versus control group; $P<0.05$ versus control group; ${ }^{\#} P<0.01$ versus OVA group.

OVA group mice compared with those of the DEX and ISO-1 groups. In the OVAsensitized/ challenged animals, GCs increased to $9.69 \pm 1.63$ per $100 \mu \mathrm{m}$ of basement membrane compared with control mice $(1.71 \pm 1.57)(P<0.01)$. ISO-1 and DEX markedly reduced airway GC hyperplasia (ISO-1, $7.60 \pm 1.29$; DEX, $3.91 \pm$ 2.06) (Figure $7, P<0.05$ and $P<0.01$ respectively). GCs in mice treated with ISO-1 or DEX but without OVA sensitization were observed to have no difference compared with those of controls (data not shown).

\section{ISO-1 Administration Decreases TGF $\beta$ I mRNA in Lung Tissue and TGF- $\beta 1$ Protein Levels in BALF}

To explore the mechanisms through which ISO-1 might offer protection against airway remodeling, we first evaluated the expression of TGF- $\beta 1 \mathrm{mRNA}$ in mice lung tissue. Compared with the control group, the OVA-challenged group had a higher expression of TGF- $\beta 1$ mRNA, whereas the DEX or ISO-1 administration group had lower expression (Table 1, Figure 8 , all $P<0.01$ ). When we measured the protein level of TGF- $\beta 1$ in BALF, we found significantly reduced TGF- $\beta 1$ protein in mice treated with ISO-1 or DEX compared with the untreated OVA group (control, $123.63 \pm 42.83 \mathrm{pg} / \mathrm{mL}$;
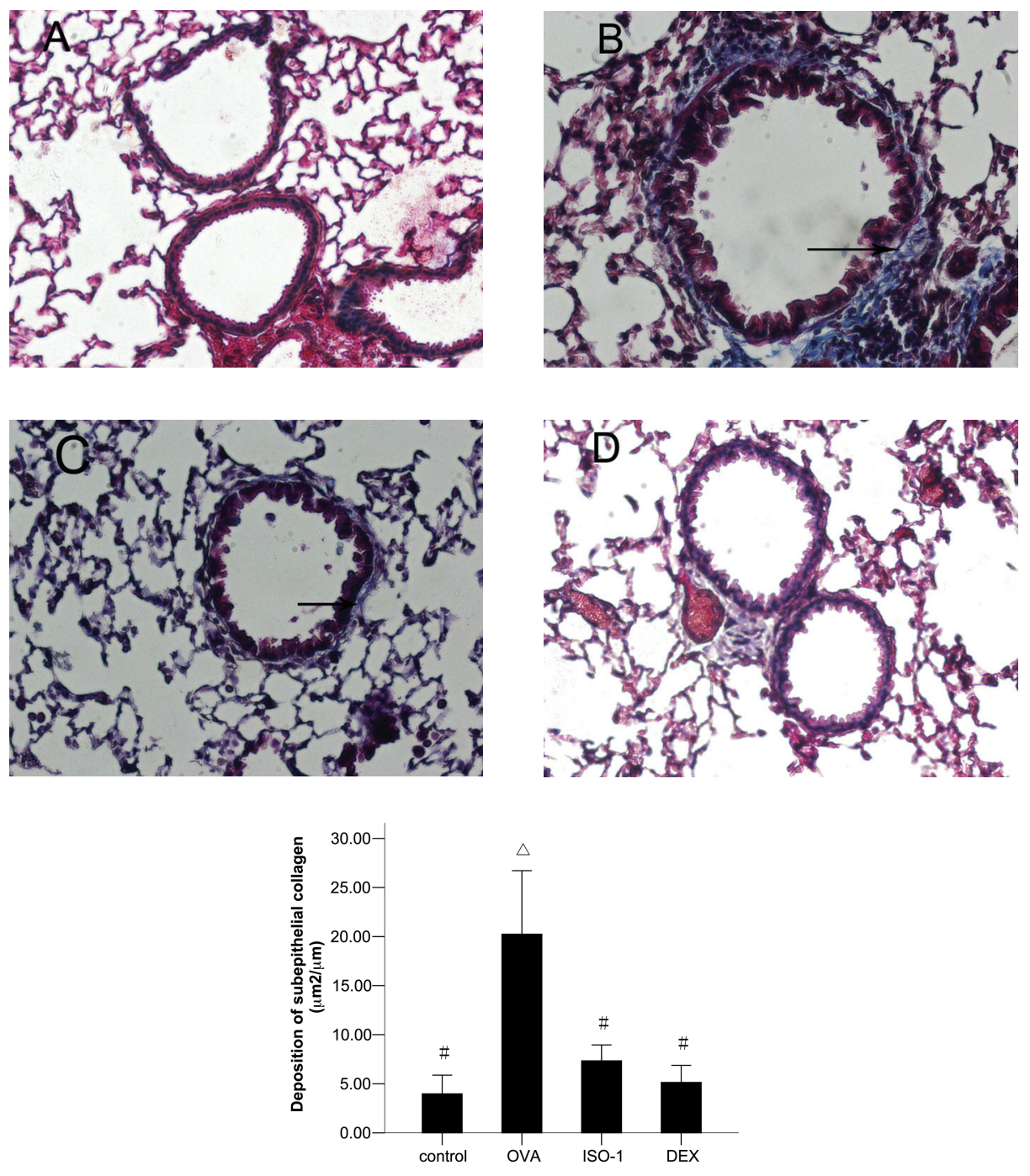

Figure 6. ISO-1 and DEX reduced OVA-induced increased subepithelial collagen deposition. Lung tissue was stained with Masson's trichrome stain (original magnification: 200x, $\mu \mathrm{m}^{2} / \mu \mathrm{m}$ ). (A) Control; (B) OVA; (C) ISO-1; (D) DEX. ${ }^{\triangle} P<0.01$ versus control group; ${ }^{\#} P<0.01$ versus OVA group.

OVA, $423.69 \pm 124.81 \mathrm{pg} / \mathrm{mL}$; ISO-1, $162.91 \pm 50.63 \mathrm{pg} / \mathrm{mL} ; \mathrm{DEX}, 146.38 \pm$ $47.13 \mathrm{pg} / \mathrm{mL}$ ) (Figure 9, all $P<0.01$ ). No significant difference in TGF- $\beta 1$ protein was observed between the ISO-1 and DEX groups $(P>0.05)$.

\section{DISCUSSION}

In this study, we employed a mouse model with characteristic features of chronic airway inflammation and remodeling similar to that observed in patients with asthma, which included eosinophil infiltration into the lung interstitium and
BALF, GC hyperplasia, increased collagen deposition around airways, airway smooth muscle thickening and airway wall thickening in the lungs. We are the first to report upregulation of MIF in BALF, airway epithelium and inflammatory cells in this model. These results are consistent with previous observations of acute inflammation in rat models of asthma (25). Our findings indicate that MIF may play a role in the induction and maintenance of asthma remodeling. In addition, we observed significantly suppressed airway inflammation after treat- 

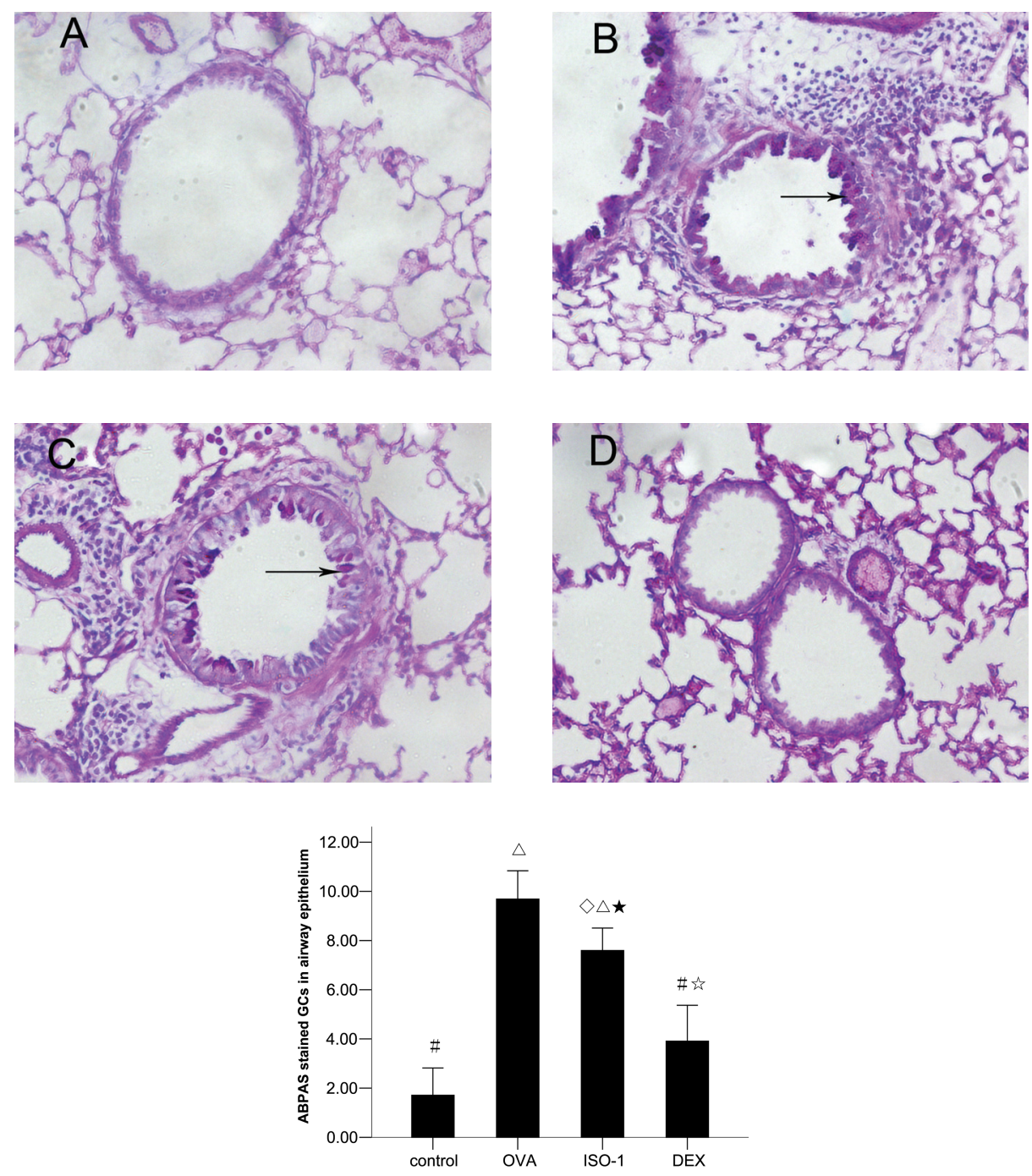

Figure 7. ISO-1 and DEX decreased OVA-induced GC metaplasia. Lung tissue was stained with Alcian blue and periodic acid-Schiff (original magnification: $\times 200$, cells per $100 \mu \mathrm{m}$ of basement membrane). (A) Control; (B) OVA; (C) ISO-1; (D) DEX. ${ }^{\triangle} P<0.01$ versus control group; $P<0.05$ versus control group; ${ }^{\#} P<0.01$ versus OVA group; ${ }^{\diamond} P<0.05$ versus $O V A$ group; ${ }^{\star} P<0.01$ versus DEX group.

ment with the MIF small molecule antagonist ISO-1. Similarly, a significant reduction in airway remodeling was found after administration of ISO-1 in OVAtreated mice. In this model, the effectiveness of ISO-1 is nearly comparable to that of DEX. It was reported that high concentrations of DEX (10-100 nmol/L) repressed MIF expression (26) and peripheral blood mononuclear cells (PBMCs) from patients treated with glucocorticoids showed a lower release of MIF in response to lipopolysaccharide, heat-killed
Escherichia coli and peptidoglycan than did PBMCs from untreated patients (27), which is consistent with our results. According to a recent report, the ISO-1 binding to the tauomerase active of MIF inhibited its proinflammantory activity (19). Thus, we postulated that ISO-1 could inhibit MIF activity but could not repress its expression. The data from our investigation indicate that antagonism of MIF may be a new target for asthmatic patients suffering from side effects of corticosteroids or resistance to glucocorticoid therapy.

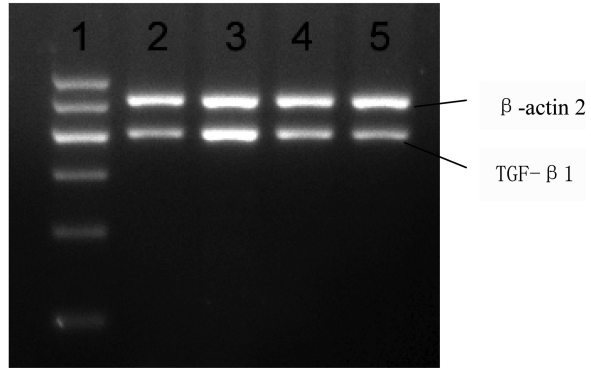

Figure 8. ISO-1 and DEX reduced OVAinduced pulmonary expression of TGF- $\beta 1$ mRNA. Lane 1: marker; lane 2: control; lane 3: OVA; lane 4: ISO-1; lane 5: DEX.

ISO-1 inhibited the infiltration of inflammatory cells at inflamed sites in OVA-sensitized mice. Several animal studies in which anti-MIF-neutralizing antibody was used have demonstrated that MIF contributes to the accumulation in inflamed sites of inflammatory cells $(28,29)$, which are associated with intercellular adhesion molecule 1 and vascular cell adhesion molecule 1 (30). However, the mechanism by which antagonism of MIF reduces infiltration of inflammatory cells remains to be elucidated. Further studies will help to shed light on this mechanism in vivo.

Eosinophilic airway inflammation is the most characteristic feature of asthma. As well as the contribution of eosinophils to acute responses, recent reports support a potential role of eosinophils in development of airway remodeling (31-33). Eosinophils are also

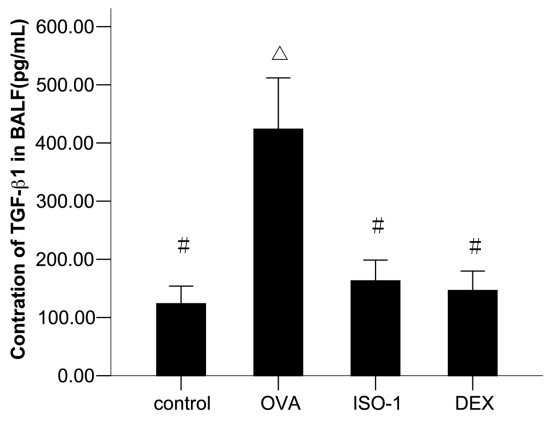

Figure 9. ISO-1 and DEX reduced OVAinduced increased TGF- $\beta 1$ levels in BALF. ${ }^{\triangle} P<0.01$ versus control group; ${ }^{*} P<0.01$ versus OVA group. 
known as major secretors of TGF- $\beta 1$ and cysteinyl leukotrienes (34), functions that further support a role for these cells in airway remodeling. In this study, we demonstrated that ISO-1 inhibited eosinophil infiltration in the lung tissue of OVA-sensitized mice, which may have contributed to inhibition of airway remodeling.

Airway thickening beneath the basement membrane occurs with deposition of collagen and other extracellular matrix proteins, including fibronectin, tenascin and laminin (35). This airway wall thickening correlates with clinically severe asthma (36) and is a prominent feature of lung tissue from patients dying with fatal asthma. In OVA-sensitized mice treated with ISO-1, we found that airway collagen deposition was significantly decreased compared with that of OVA-sensitized mice. These data indicate an important role of MIF in collagen deposition/lung fibrosis in this model of chronic asthma.

Subepithelial fibrosis is a distinctive feature of airway remodeling and contributes to the thickened airway walls $(35,37)$, and excessive mucus secretion from hyperplastic GCs is also a feature of airway remodeling (38). The results we report here demonstrate that continuous treatment with ISO-1 reduced the development of GC hyperplasia, but the GC levels were still significantly higher than in DEX-treated mice. These findings suggest a limited role of ISO-1 in reducing GC hyperplasia.

Another important aspect of airway remodeling, which has been linked to asthma severity and was assumed to contribute to the development of airway hyperresponsiveness (39), is the increase of smooth muscle mass in asthmatic airways. We found that ISO-1 treatment significantly reduced airway smooth muscle hypertrophy, which indicates that MIF is an important mediator of the increase in airway smooth muscle observed after repeated allergen challenge. The mechanism of this mediation effect remains obscure, however. Michell and colleagues showed that both endogenously secreted and exogenously added MIF stimulated the proliferation of NIH/3T3 cells (40). Whether MIF could also stimulate the proliferation of ASMC requires further study.

TGF- $\beta 1$ represents a profibrotic cytokine that is produced by a number of cells, including macrophages, epithelial cells, fibroblasts and eosinophils. TGF- $\beta 1$ is known to enhance the fibrotic process by augmenting fibroblast growth and collagen production, as well as promoting differentiation of fibroblasts into myofibroblasts that secrete collagen and other extracellular matrix components (41). In addition, increased expression of TGF- $\beta 1$ was observed in the airways of patients with asthma, correlating with disease severity and degree of subepithelial fibrosis (42). We also examined TGF- $\beta 1$ expression in the present model of murine asthma. Consistent with these previous findings, our results have shown that expression of TGF- $\beta 1$ was increased after OVA challenge, and administration of ISO-1 in OVA-induced mice decreased the increased expression of TGF- $\beta 1$. The result is similar to that of Leung et al., who showed that anti-MIF treatment resulted in decreased renal expression of TGF- $\beta 1$ in an experimental model of immunoglobulin-A nephropathy (15). Thus we hypothesize that ISO-1 may inhibit mice airway remodeling through reduction of the expression of TGF- $\beta 1$.

In conclusion, our study demonstrates that MIF small-molecule antagonism has a significant antiinflammatory effect on allergen-induced lung inflammation and can prevent changes in airway remodeling in this mouse model of asthma. In the future, antagonism of MIF may be an attractive alternative therapy for some asthmatic patients.

\section{DISCLOSURE}

The authors declare that they have no competing interests as defined by Molecular Medicine, or other interests that might be perceived to influence the results and discussion reported in this paper.

\section{REFERENCES}

1. Roche WR, Beasley R, Williams JH, Holgate ST. (1989) Subepithelial fibrosis in the bronchi of asthmatics. Lancet. 1:520-4.

2. Aikawa T, Shimura S, Sasaki H, Ebina M, Takishima T. (1992) Marked goblet cell hyperplasia with mucus accumulation in the airways of patients who died of severe acute asthma attack. Chest. 101:916-21.

3. Wiggs BR, Bosken C, Paré PD, James A, Hogg JC. (1992) A model of airway narrowing in asthma and in chronic obstructive pulmonary disease. Am. Rev. Respir. Dis. 145:1251-8.

4. Barnes PJ. (1998) Anti-inflammatory actions of glucocorticoids: molecular mechanisms. Clin. Sci. (Lond). 94:557-72.

5. Boulet LP, et al. (2000) Airway hyperresponsiveness, inflammation, and subepithelial collagen deposition in recently diagnosed versus long-standing mild asthma. Influence of inhaled corticosteroids. Am. J. Respir. Crit. Care Med. 162:1308-13.

6. Irwin RS, Richardson ND. (2006) Side effects with inhaled corticosteroids: the physician's perception. Chest. 130:41S-53S

7. Leung DY, Bloom JW. (2003) Update on glucocorticoid action and resistance. J. Allergy Clin. Immunol. 111:3-22.

8. Szefler SJ, et al. (2002) Significant variability in response to inhaled corticosteroids for persistent asthma. J. Allergy Clin. Immunol. 109:410-8.

9. Drazen JM, Silverman EK, Lee TH. (2000) Heterogeneity of therapeutic responses in asthma. $\mathrm{Br}$. Med. Bull. 56:1054-70.

10. Chan MT, Leung DY, Szefler SJ, Spahn JD. (1998) Difficult-to-control asthma: clinical characteristics of steroid-insensitive asthma. J. Allergy Clin. Immunol. 101:594-601.

11. Calandra T, et al. (1995) MIF as a glucocorticoidinduced modulator of cytokine production. $\mathrm{Na}$ ture. 377:68-71.

12. Magalhães ES, et al. (2007) Macrophage migration inhibitory factor is essential for allergic asthma but not for Th2 differentiation. Eur. J. Immunol. 37:1097-106.

13. Mizue $Y$, et al. (2005) Role of macrophage migration inhibitory factor in asthma. Proc. Natl. Acad. Sci. U. S. A. 102:14410-5.

14. Amano T, Nishihira J, Miki I. (2007) Blockade of macrophage migration inhibitory factor (MIF) prevents the antigen-induced response in a murine model of allergic airway inflammation. Inflamm. Res. 56:24-31.

15. Leung JC, et al. (2004) Anti-macrophage migration inhibitory factor reduces transforming growth factor-beta 1 expression in experimental IgA nephropathy. Nephrol. Dial. Transplant. 19:1976-85.

16. Chen G, Khalil N. (2006) TGF-beta1 increases proliferation of airway smooth muscle cells by phosphorylation of map kinases. Respir. Res. 7:2.

17. Holgate ST. (2000) Epithelial damage and response. Clin. Exp. Allergy 1:37-41. 
18. Zhang S, Smartt H, Holgate ST, Roche WR. (1999) Growth factors secreted by bronchial epithelial cells control myofibroblast proliferation: an in vitro co-culture model of airway remodeling in asthma. Lab. Invest. 79:395-405.

19. Al-Abed Y, et al. (2005) ISO-1 binding to the tautomerase active site of MIF inhibits its proinflammatory activity and increases survival. J. Bio. Chem. 280:36541-4.

20. Jain VV, et al. (2002) CpG-oligodeoxynucleotides inhibit airway remodeling in a murine model of chronic asthma. J. Allergy. Clin. Immunol. 110:867-72.

21. Henderson WR Jr, et al. (2002) A role for cysteinyl leukotrienes in airway remodeling in a mouse asthma model. Am. J. Respir. Crit. Care Med. 165:108-16.

22. Bai A, et al. (1994) Proposed nomenclature for quantifying subdivisions of the bronchial wall. J. Appl. Physiol. 77:1011-4.

23. Opazo Saez A, Du T, Wang NS, Martin JG. (1996) Methacholine-induced bronchoconstriction and airway smooth muscle in the guinea pig. J. Appl. Physiol. 80:437-44.

24. Vanacker NJ, Palmans E, Kips JC, Pauwels RA. (2001) Fluticasone inhibits but does not reverse allergen-induced structural airway changes. Am. J. Respir. Crit. Care Med. 163:674-9.

25. Kobayashi M, et al. (2006) Role of macrophage migration inhibitory factor in ovalbumininduced airway inflammation in rats. Eur. Respir. J. 27:726-34

26. Alourfi Z, et al. (2005) Glucocorticoids suppress macrophage migration inhibitory factor (MIF) expression in a cell-type-specific manner. J Mol. Endocrinol. 34:583-95.

27. Maxime V, Fitting C, Annane D, Cavaillon JM. (2005) Corticoids normalize leukocyte production of macrophage migration inhibitory factor in septic shock. J. Infect. Dis. 191:138-44.

28. Lan HY, et al. (1997) The pathogenic role of macrophage migration inhibitory factor in immunologically induced kidney disease in the rat. J. Exp. Med. 185:1455-65.

29. Huang XR, et al. (2001) Macrophage migration inhibitory factor is an important mediator in the pathogenesis of gastric inflammation in rats. Gastroenterology. 121:619-30.

30. Amin MA, et al. (2006) Migration inhibitory factor up-regulates vascular cell adhesion moleculeand intercellular adhesion molecule-1 via Src, PI3 kinase, and NFkappaB. Blood. 107:2252-61.

31. Flood-Page P, et al. (2003) Anti-IL-5 treatment reduces deposition of ECM proteins in the bronchial subepithelial basement membrane of mild atopic asthmatics. J. Clin. Invest. 112:1029-36.

32. Cho JY, et al. (2004) Inhibition of airway remodeling in IL-5-deficient mice. J. Clin. Invest. 113:551-60.

33. Humbles AA, et al. (2004) A critical role for eosinophils in allergic airways remodeling. Science. 305:1776-9.

34. Ohno I, et al. (1996) Transforming growth factor beta 1 (TGF beta 1 ) gene expression by eosinophils in asthmatic airway inflammation. Am. J. Respir. Cell Mol. Biol. 15:404-9.

35. Elias JA, Zhu Z, Chupp G, Homer RJ. (1999) Airway remodeling in asthma. J. Clin. Invest. 104:1001-6.

36. Boulet LP, et al. (1997) Bronchial subepithelial fibrosis correlates with airway responsiveness to methacholine. Chest. 112:45-52.

37. Busse W, Elias J, Sheppard D, Banks-Schlegel S. (1999) Airway remodeling and repair. Am. J. Respir. Crit. Care Med. 160:1035-42.

38. Wanner A. (1990) The role of mucus in chronic obstructive pulmonary disease. Chest. 97:11S-5S.

39. Benayoun L, Druilhe A, Dombret MC, Aubier M, Pretolani M. (2003) Airway structural alterations selectively associated with severe asthma. Am. J. Respir. Crit. Care Med. 167:1360-8.

40. Mitchell RA, Metz CN, Peng T, Bucala R. (1999) Sustained mitogen-activated protein kinase (MAPK) and cytoplasmic phospholipase A2 activation by macrophage migration inhibitory factor (MIF). Regulatory role in cell proliferation and glucocorticoid action. J Biol. Chem. 274:18100-6.

41. Batra V, et al. (2004) Bronchoalveolar lavage fluid concentrations of transforming growth factor (TGF)-beta1, TGF-beta2, interleukin (IL)-4 and IL-13 after segmental allergen challenge and their effects on alpha-smooth muscle actin and collagen III synthesis by primary human lung fibroblasts. Clin. Exp. Allergy. 34:437-44.

42. Minshall EM, et al. (1997) Eosinophil-associated TGF-beta1 mRNA expression and airways fibrosis in bronchial asthma. Am. J. Respir. Cell Mol. Biol. 17:326-33. 